\title{
Ethnopharmacology and phytochemistry-based review on the antimalarial potential of Acacia pennata (L.) Willd.
}

\author{
James H. Zothantluanga* \\ Department of Pharmaceutical Sciences, Dibrugarh University, Dibrugarh 786004, Assam, India
}

\begin{abstract}
A protozoan infection called malaria is caused by Plasmodium parasites. In 2018, it infected more than 228 million people and caused 405,000 fatalities. Worryingly, the present antimalarial drugs had developed drug resistance. Furthermore, they are associated with adverse effects and price issues. Amidst the gloomy scenario, drug discovery based on natural products had renewed the hope to overcome the burdens associated with the present antimalarial drugs. Auspiciously, medicinal plants had contributed significantly to the modern pharmacotherapy of malaria. Interestingly, Acacia pennata (L.) Willd. was also documented as a traditional antimalarial agent. However, there is still no scientific evidence regarding its antimalarial activity. Therefore, this article was aimed to study the phytochemical profile of $A$. pennata and explore their potential activity against malarial parasites. A. pennata contains different classes of bioactive compounds such as alkaloids, flavonoids, phenols, glycosides, terpenoids, phytosterols, and saponins whose antimalarial activities had been reported. Accordingly, the future scopes and challenges regarding the possible antimalarial activity for $A$. pennata are also discussed. To maximize the chances for finding a new antimalarial chemical entity from $A$. pennata, a schematic flow chart on the ethnopharmacology based drug discovery approach is also provided. Thus, this literary work may be used by researchers as a referential guide in the search for new antimalarial phytochemicals.
\end{abstract}

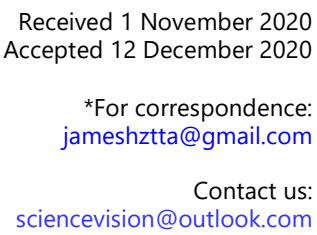

Received 1 November 2020 Accepted 12 December 2020

*For correspondence: jameshztta@gmail.com

Contact us: sciencevision@outlook.com

Keywords: Acacia pennata, antimalarial, bioactive compound, ethnopharmacology, phytochemistry, secondary metabolites.

\section{Introduction}

Malaria is a protozoan infection caused by Plasmodium (Marchiafava \& Celli, 1885) parasites. Although malaria is an infectious disease, it is treatable and can be prevented. With a single bite, a female Anopheles mosquito transmits malarial parasites $(P$. knowlesi, $P$. ovale, $P$. falciparum, $P$. vivax, and $P$. malariae) into the blood of humans. ${ }^{1,2} A$ total of 228 million cases of malaria with 405,000 fatalities were recorded in the year $2018 .^{3} P$. falciparum is responsible for inducing cerebral malaria, i.e. the most fatal form of malaria and in general, $P$. vivax and $P$. falciparum seems to be more harmful. ${ }^{2,4}$ Few 

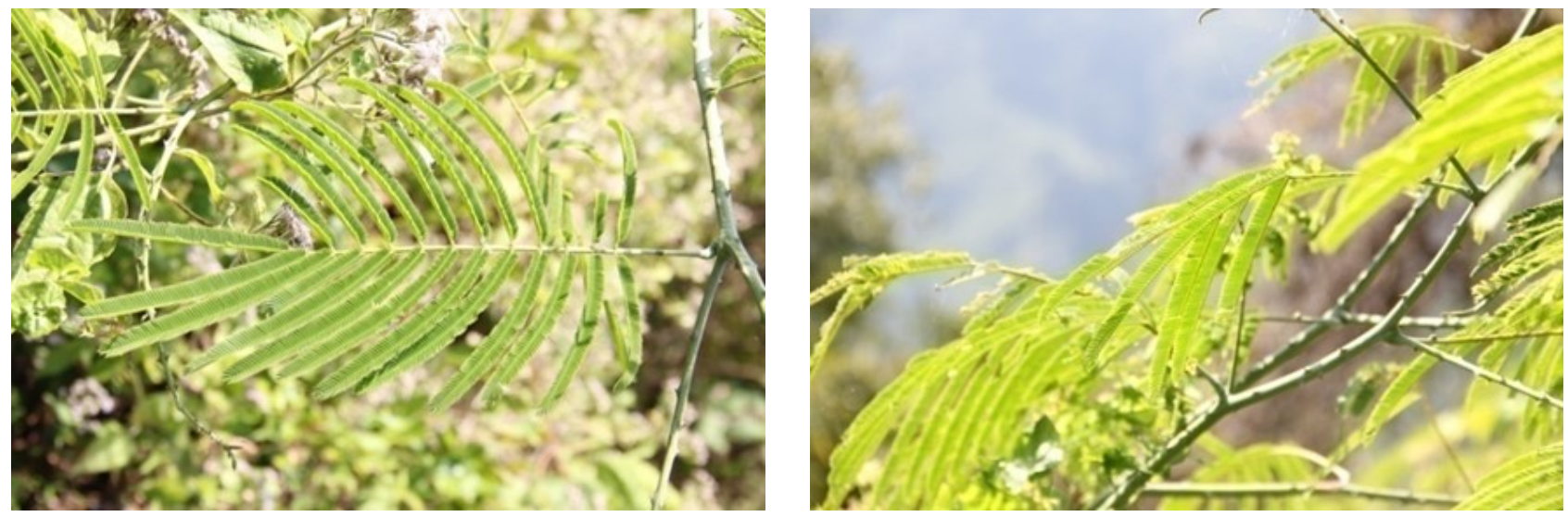

Figure 1 | Leaves and stem of $A$. pennata (Image courtesy: Zothantluanga et al., 2020 ${ }^{17}$ ).

examples of antimalarial drugs are quinine, chloroquine, mefloquine, primaquine, amodiaquine, artemether, artesunate, atovaquone, lumefantrine, sulfadoxine and pyrimethamine. ${ }^{5}$

Problems such as adverse effects, drug resistance, and price issues are associated with the present antimalarial drugs. ${ }^{6-9}$ Therefore, scientists had renewed their interests in natural product-based drug discovery with the hope to overcome the burdens associated with the present antimalarial drugs. ${ }^{10}$ Providentially, it is a relief to state that a significant contribution was already made by plant derivatives (for instance, quinine and artemisinin) in the pharmacotherapy of malaria. ${ }^{11,12}$ Moreover, the phytotherapy of malaria included more than 1200 and 160 species of plants and families respectively. ${ }^{12}$
Therefore, the chances to find a newer and safer antimalarial drug might be increased by examining the correlation between the ethnopharmacological knowledge and the phytochemistry of a plant.

Laldinsanga et al. ${ }^{13}$ recorded Acacia pennata (L.) Willd. (Figure 1) as a traditional medicine against malaria. A. pennata (Family: Fabaceae) is a large thorny plant found in Bangladesh, Bhutan, India, Myanmar, Southwest China, Sri Lanka, Thailand and Vietnam. ${ }^{14-16}$ There are plenty of nutrients present in $A$. pennata (Figure 2) that accounts for its nutraceutical potential. ${ }^{15}$ However, specifications on the plant part, method of preparation, route of administration, and dosing regimen adopted for the traditional treatment against malaria were missing. Moreover, there is no scientific evidence on the

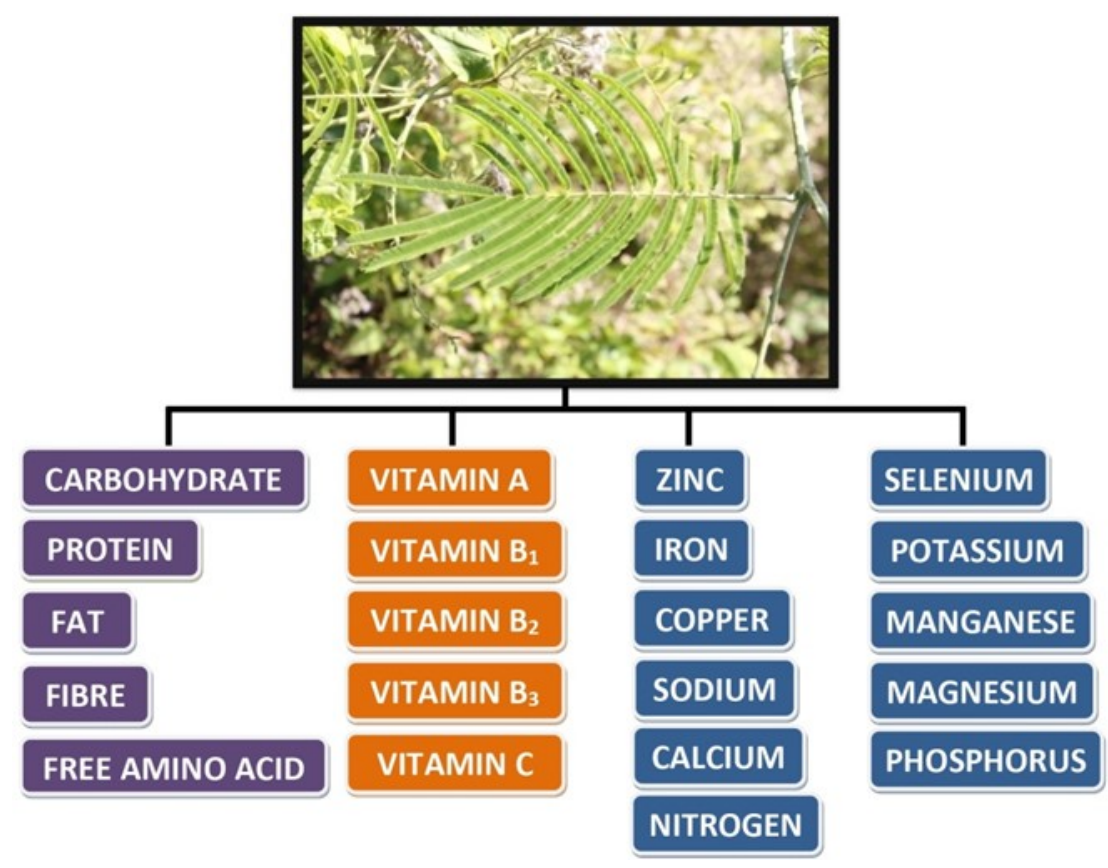

Figure 2 | Nutrients present in $A$. pennata. 


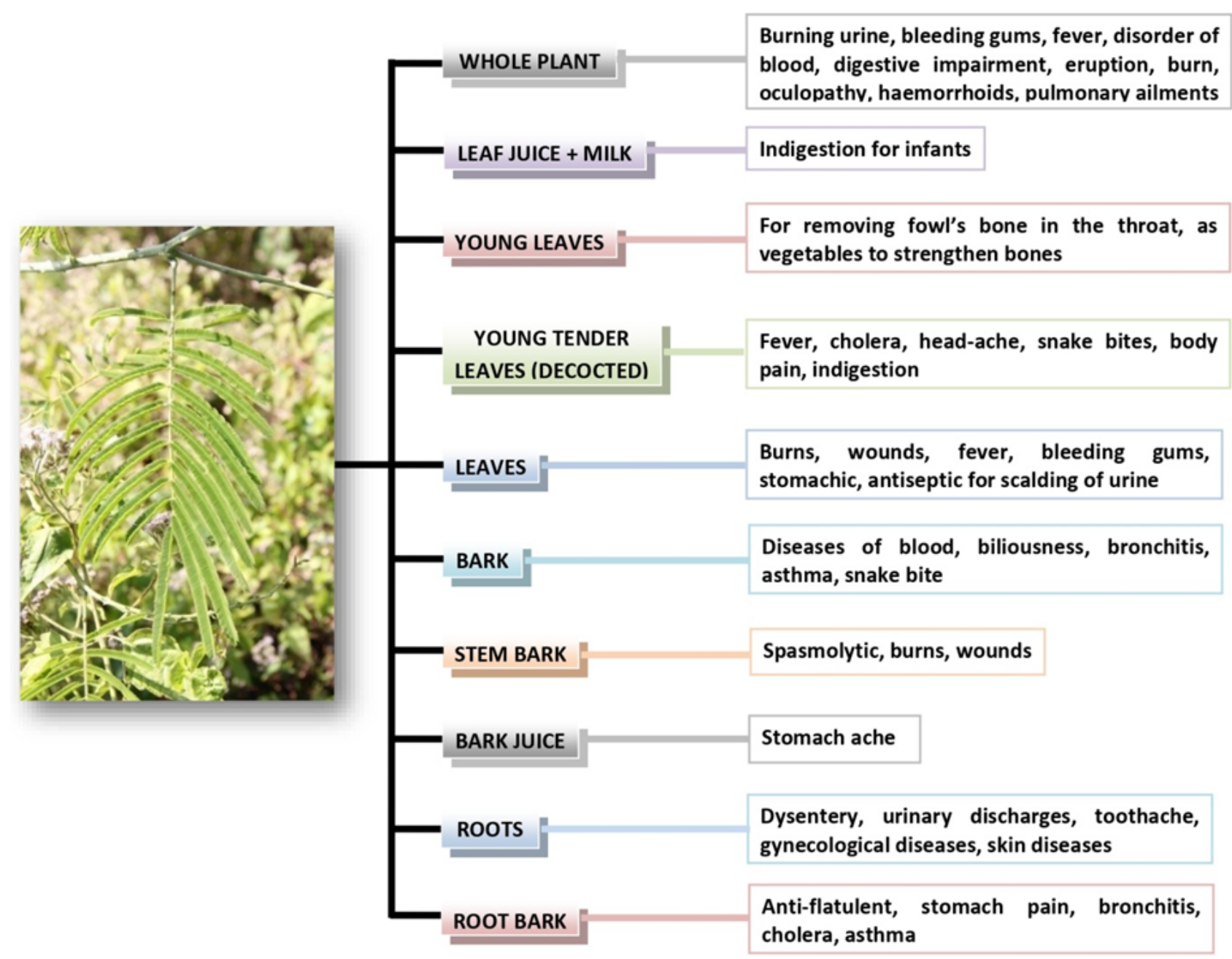

Figure 3 | Traditional indications for $A$. pennata.

antimalarial activity of $A$. pennata. Therefore, this article was aimed to systematically explore the antimalarial potential of $A$. pennata based on its phytochemical profile.

\section{Phytopharmacology of Acacia pennata and evidences for their antimalarial activity}

A. pennata is traditionally used for many health ailments (Figure 3 ) and had been investigated for a handful of pharmacological activities (Figure 4). 15,17 Though the scientific evidence on the antimalarial activity of $A$. pennata is still not available, the phytochemical profile of $A$. pennata might provide some theoretical evidence that supports the traditional claim. The different classes of bioactive compounds present in $A$. pennata were identified to be alkaloids, flavonoids, glycosides, phenols, phytosterols, terpenoids and saponins. $15,17,18$

Alkaloids are biologically active nitrogencontaining compounds that are found in plants, animals, bacteria, and fungi. Alkaloids exhibit various pharmacological activities such as sympathomimetic, anticholinergic, antiulcer, antiviral, antidepressant, analgesic, anti-inflammatory, muscle relaxant, diuretic, antitumor, antimicrobial and antihypertensive. ${ }^{19} \mathrm{Ma}$ et $a l .{ }^{20}{ }^{20} \mathrm{Kubo}$ et $a l^{21}$ and Promchai et al. ${ }^{22}$ had reported the antimalarial activity of alkaloids.

Flavonoids are naturally occurring polyphenolic compounds. They are an important secondary metabolites of plants and are widely distributed in vegetables and fruits. Owing to their anti-cancer, anti -mutagenic, anti-inflammatory, and antioxidant properties, flavonoids form a key element in many medicinal, nutraceutical, cosmetic, and pharmaceutical applications. ${ }^{23}$. The antimalarial activity of flavonoids had been reported by Ichino et al. ${ }^{24}$ Khaomek et al. ${ }^{25}$ and Penna-Coutinho et al. ${ }^{26}$

Glycosides are bioactive compounds that attaches itself to an aglycone via a glycosidic bond. The glycoside moiety plays a crucial role in altering the pharmacology and pharmacokinetic profiles of the aglycone moiety. Glycosidic antibiotics, 


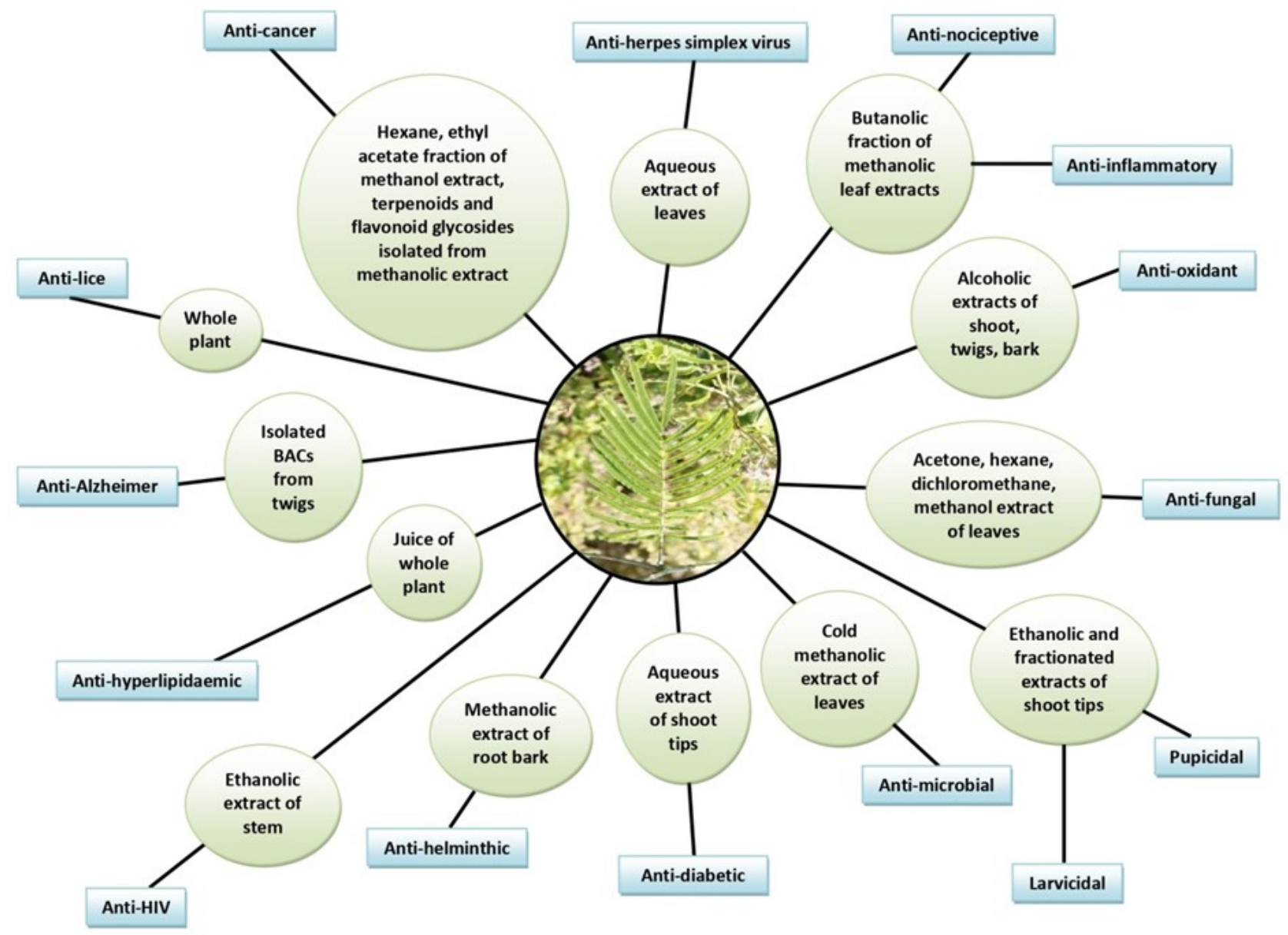

Figure 4 | Pharmacological activities of $A$. pennata.

glycosides of vitamins, alkaloid glycosides, steroid glycosides, terpenoid glycosides, and polyphenol glycosides are different classes of glycosides having a great value in health care. $^{27}$ Graziose et al., ${ }^{28}$ Ovenden et al. ${ }^{29}$ and Park et al. ${ }^{30}$ had reported the antimalarial activity of glycosides. ${ }^{28-30}$

Phenols and polyphenols are secondary metabolites present in most of the plants. The $C_{6}-C_{3}$ phenylpropanoid pathway is responsible for biosynthesizing various plant phenols that have biological activities like antioxidant, anti-microbial, anti-inflammatory, anti-cancer, anti-allergenic, antihypertensive, anti-thrombogenic and anti-platelet. ${ }^{31}$ The antimalarial activity of phenols had been reported by Laphookhieo et al., ${ }^{32}$ Morimoto et al. ${ }^{33}$ and Alson et al. ${ }^{34}$.

Phytosterols (also known as plant sterols) are present in all plant cells. Structurally, they differ from cholesterol and they belong to the family of triterpene. They act as precursors in the biosynthesis of bioactive compounds like steroidal glycoalkaloids, steroidal saponins, brassinosteroids, and phytoecdysteroids. In general, they exhibited antiproliferative, antimicrobial, immunoprotective, hepatoprotective, nephroprotective, adaptogenic, anabolic, hypoglycaemic, hypocholesterolemic, and neuromodulatory activities. ${ }^{35}$ Irungu et $a l^{36}$ and Perumal et al. ${ }^{37}$ had reported the antimalarial activity of phytosterols. ${ }^{36,37}$

Terpenoids serve as a wealthy reservoir for potential drug candidates. Among all the classes of natural products, they are the biggest class. ${ }^{38}$ Terpenoids have pharmacological activities like antimicrobial, anti-cancer, anti-nociceptive, hepatoprotective, anti-foaming, carminative and antiinflammatory activities. ${ }^{39}$ The antimalarial activity of terpenoids had been reported by Saewan et al., ${ }^{40}$ Chukwujekwu et al. ${ }^{41}$ and Greve et al. ${ }^{42}$

Saponins comprises of a large number of biologically active triterpene glycosides or steroids that are distributed throughout the marine animal and plant kingdoms. Saponins elicit a vast array of pharmacological activities such as immunemodulation, anti-cancer, anti-phlogistic, anti-allergic, 
anti-hepatotoxic, anti-viral, anti-diabetic, and antifungal. ${ }^{43}$ Ohigashi et al., ${ }^{44}$ Traore et al. ${ }^{45}$ and Akanbi et $a l^{46}$ had reported the antimalarial activity of saponins. $^{44-46}$

\section{Future Challenges}

A pre-clinical study (in vitro and in vivo) is a stage of the drug development process that precedes clinical trials wherein the safety and efficacy data of a drug candidate are collected. ${ }^{47,48}$ Worryingly, adverse effects that are induced by natural products had been reported. ${ }^{49}$ Thus, it is important to consider the toxicity issues that might be associated with natural products. Therefore, pre-clinical techniques may be used to generate data on the pharmacological efficacy, safety as well as toxicity of a potential drug candidate.

Different classes of bioactive compounds like alkaloids, flavonoids, glycosides, phenols, saponins, phytosterols, and terpenoids had been investigated for their antimalarial activity. ${ }^{20-22,24-26,28-30,32-34,36,37,40-}$ 42,44-46 Auspiciously, all these classes of bioactive compounds are present in $A$. pennata. ${ }^{15,17,18}$ Moreover, it is worthy to re-state that $A$. pennata still lacks scientific evidence for antimalarial activity. Therefore, the extracts and fractions obtained from A. pennata may be investigated for their activity against malarial parasites using suitable pre-clinical techniques. Based on the results obtained from the pre-clinical study wherein various extracts and fractions of $A$. pennata will be used, bioactivity guided isolation of compounds may also be carried out.

On the other hand, there is no assurance that $A$. pennata will show antimalarial activity on account simply because it contained the classes of bioactive compounds whose anti-malarial activities had been reported. This is because the specific antimalarial phytochemical present under the same class of a

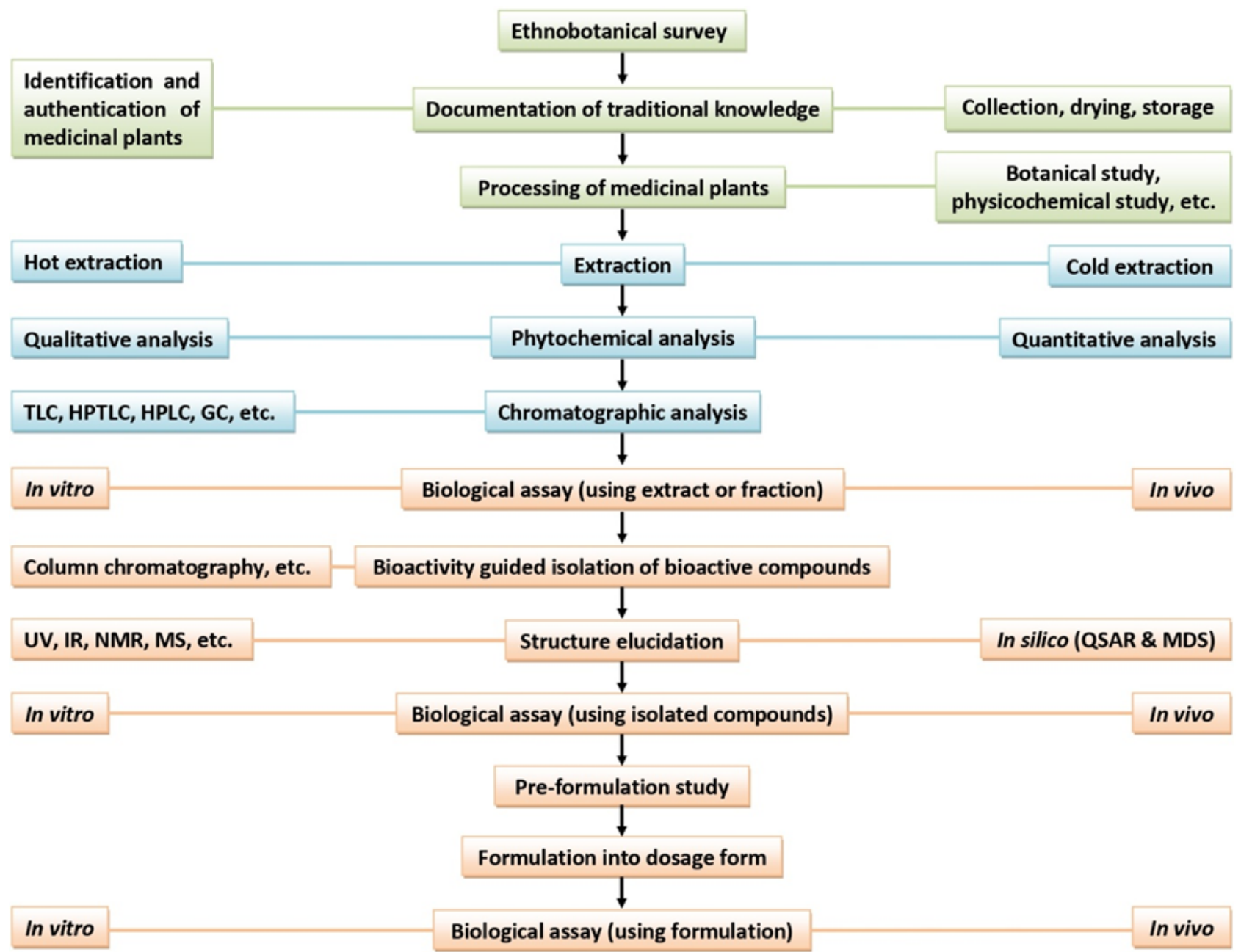

Figure 5 | Ethnopharmacological-based approach for discovering a new chemical entity (TLC = thin layer chromatography; HPTLC = high performance thin layer chromatography; HPLC = high performance liquid chromatography; GC = gas chromatography; UV = ultraviolet; IR = infra-red; NMR = nuclear magnetic resonance; MS = mass spectroscopy; QSAR = quantitative structure activity relationship; MDS = molecular docking study). 
bioactive compound might differ in different plants. For example, two of the most widely used antimalarial drugs i.e. quinine (alkaloid) and artemisinin (terpenoid) are examples of bioactive compounds that had been isolated from Cinchona officinalis and Artemesia annua respectively. ${ }^{50-53}$ Thus, although $A$. pennata was reported to contain alkaloids and terpenoids, ${ }^{17,18}$ quinine and artemisinin were never reported to be isolated from $A$. pennata. Still, the possibility of $A$. pennata as having its antimalarial phytochemicals cannot be completely ruled out. Therefore, in addition to the attempt to isolate the bioactive compounds from $A$. pennata and screen their activity against malarial parasites, in silico techniques may also be utilized to screen the antimalarial activity of the known phytochemicals that are present in $A$. pennata.

Ligand-based drug-design involves the study of quantitative structure-activity relationship (QSAR) while structure-based drug-design involves molecular docking study (MDS). These approaches for in silico drug discovery falls under the category of computer-aided drug design that utilizes a library of known compounds. ${ }^{54,55}$ Interestingly, it was reported that many phytochemicals had been isolated from $A$. pennata. ${ }^{15}$ Therefore, the QSAR technique may be utilized to investigate the relationship between the pharmacological activity and chemical structure of the phytochemicals so that appropriate structure modifications may be made to yield a more potent and safer compound. Also, in silico screening of isolated phytochemicals of $A$. pennata for their antimalarial activity may be carried out with the MDS technique. Hence, further pharmacological investigations will depend on the results that are provided by the MDS technique. This can also prevent unnecessary loss of money and time.

In light of the above discussions, a modified ethnopharmacology-based drug discovery approach that was adapted from Brusotti et al. ${ }^{56}$ and Novaes and Leite ${ }^{57}$ is schematically represented in Figure 5. However, the ethnopharmacology based approach that is depicted in Figure 5 is a hypothetical proposal that might not be fully applicable for every research. Still, as it might aid in the search for new antimalarial drugs, it may be considered as a basic and referential blueprint that may be upgraded and modified as per personal requirements. Thus, the ethnopharmacological based approach might increase the chances of discovering a new chemical entity.

\section{Conclusion}

Review of the phytochemical profile of Acacia pennata reveals the antimalarial potential that is on par with the traditional claim.

\section{Conflict of interest}

Not applicable.

\section{References}

1. Basu, S., Sahi, P.K. (2017). Malaria: An update. Indian Journal of Paediatrics. 84, 521-528. https://doi.org/10.1007/s12098-017-2332-2.

2. World Health Organization. (2020). Malaria. https://www.who.int/news-room/fact-sheets/detail/ malaria (15 August 2020).

3. World Health Organization. (2020). The "World Malaria Report 2019" at a glance. https:// www.who.int/news-room/feature-stories/detail/worldmalaria-report-2019 (15 August 2020).

4. Singh, N., Kaushik, N.K., Mohanakrishnan, D., Tiwari, S.K., Sahal, D. (2015). Antiplasmodial activity of medicinal plants from Chhotanagpur plateau, Jharkhand, India. Journal of Ethnopharmacology, 165, 152-162. https:// doi.org/10.1016/j.jep.2015.02.038.

5. Baird, J.K. (2005). Effectiveness of Antimalarial Drugs. New England Journal of Medicine, 352, 15651577. https://doi.org/10.1056/nejmra043207.

6. Gachelin, G., Garner, P., Ferroni, E., Verhave, J.P., Opinel, A. (2018). Evidence and strategies for malaria prevention and control: a historical analysis. Malaria Journal, 17, 96. https:// doi.org/10.1186/s12936-018-2244-2.

7. Memvanga, P.B., Tona, G.L., Mesia, G.K., Lusakibanza, M.M., Cimanga, R.K. (2015). Antimalarial activity of medicinal plants from the Democratic Republic of Congo: A review. Journal of Ethnopharmacology, 169, 76-98. https:// doi.org/10.1016/j.jep.2015.03.075.

8. Okell, L.C., Griffin, J.T., Roper, C. (2017). Mapping sulphadoxine-pyrimethamine-resistant

Plasmodium falciparum malaria in infected humans and in parasite populations in Africa. Scientific Reports, 7, 7389. https://doi.org/10.1038/s41598-01706708-9.

9. Menard, D., Dondorp, A. (2017). Antimalarial Drug Resistance: A Threat to Malaria Elimination. Cold Spring Harbor Perspectives in Medicine, 7, a025619. https://doi.org/10.1101/ cshperspect.a025619.

10. Rawat, P., Singh, P.K., Kumar, V. (2017). Evidence based traditional anti-diarrheal medicinal plants and their phytocompounds. Biomedicine $\mathcal{E}$ pharmacotherapy, 96, 1453-1464. https:// doi.org/10.1016/j.biopha.2017.11.147. 
11. Chinsembu K.C. (2015). Plants as antimalarial agents in Sub-Saharan Africa. Acta Tropica, 152, 32 -48 . https://doi.org/10.1016/ j.actatropica.2015.08.009.

12. Odoh, U.E., Uzor, P.F., Eze, C.L., Akunne, T.C., Onyegbulam, C.M., Osadebe, P.O. (2018). Medicinal plants used by the people of Nsukka Local Government Area, south-eastern Nigeria for the treatment of malaria: An ethnobotanical survey. Journal of Ethnopharmacology, 218, 1-15. https://doi.org/10.1016/j.jep.2018.02.034.

13. Laldinsanga, Sarma, H., Jahan, T., Goswami, A.K., Sharma, R., Sharma, H.K. (2019). Traditional antimalarial drugs from Serchhip and Lunglei districts of Mizoram. Current Trends in Pharmaceutical Research, 6, 76-104.

14. India Biodiversity Portal. (2020). Acacia pennata (L.) Willd, https://indiabiodiversity.org/species/show/32012 (27 August 2020).

15. Zothantluanga, J.H., Bhat, H.R., and Shakya, A. (2019). A systematic review on the nutraceutical potential of Acacia pennata (L.) Willd. Current Trends in Pharmaceutical Research, 6, 12-27.

16. Nguyen, V.D., Nguyen, H.L.T., Do, L.C., Tuan, V.V., Thuong, P.T., and Phan, T.N. (2018). A new saponin with anti-HIV-1 protease activity from Acacia pennata. Natural Product Communications, 13, 411-414.

https://doi.org/10.1177\% 2F1934578X1801300408.

17. Zothantluanga, J.H., Sailo, N., Paul, A., and Shakya, A. (2020). Pharmacognostical characterization and in vitro antioxidant activity of Acacia pennata (L.) Willd. leaves: A Southeast Asian medicinal plant. Science Vision, 20, 16-28. https://doi.org/10.33493/scivis.20.01.02.

18. Lomarat, P., Chancharunee, S., Anantachoke, N., Kitphati, W., Sripha, K., Bunyapraphatsara, N. (2015). Bioactivity-guide separation of the active compounds in Acacia pennata responsible for the prevention of Alzheimer's disease. Natural Product Communications, 10, 1431-1434. https:// doi.org/10.1177\%2F1934578X1501000830.

19. Alves de Almeida, A.C., de Faria, F.M., Dunder, R.J., Manzo, L.P.B., Souza-Brito, A.R. M., LuizFerreira, A. (2017). Recent trends in pharmacological activity of alkaloids in animal colitis: potential use for inflammatory bowel disease. Evidence-Based Complementary and Alternative Medicine, 1-24. https:// doi.org/10.1155/2017/8528210.

20. Ma, G., Sun, Z., Sun, Z., Yuan, J., Wei, H., Yang, J., $\mathrm{Wu}, \mathrm{H} ., \mathrm{Xu}, \mathrm{X}$. (2014). Antimalarial diterpene alkaloids from the seeds of Caesalpinia minax. Fitoterapia, 95, 234-239. https:// doi.org/10.1016/j.fitote.2014.04.001.

21. Kubo, M., Yatsuzuka, W., Matsushima, S., Harada, K., Inoue, Y., Miyamoto, H., Matsumoto, M., Fukuyama, Y. (2016). Antimalarial phenanthroindolizine alkaloids from Ficus septica. Chemical \& Pharmaceutical Bulletin, 64, 957960. https://doi.org/10.1248/cpb.c16-00181.

22. Promchai, T., Jaidee, A., Cheenpracha, S., Trisuwan, K., Rattanajak, R., Kamchonwongpaisan, S., Laphookhieo, S., Pyne, S.G., Ritthiwigrom, T. (2016). Antimalarial oxoprotoberberine alkaloids from the leaves of Miliusa cuneata. Journal of natural products, 79, 978983. https://doi.org/10.1021/acs.jnatprod.5b01054.

23. Panche, A.N., Diwan, A.D., Chandra, S.R. (2016). Flavonoids: an overview. Journal of Nutritional Science, 5, e47. https://doi.org/10.1017/jns.2016.41.

24. Ichino, C., Kiyohara, H., Soonthornchareonnon, N., Chuakul, W., Ishiyama, A., Sekiguchi, H., Namatame, M., Otoguro, K., Omura, S., Yamada, H. (2006). Antimalarial activity of biflavonoids from Ochna integerrima. Planta Medica, 72, 611-614. https://doi.org/10.1055/s-2006-931569.

25. Khaomek, P., Ichino, C., Ishiyama, A., Sekiguchi, H., Namatame, M., Ruangrungsi, N., Saifah, E., Kiyohara, H., Otoguro, K., Omura, S., Yamada, H. (2008). In vitro antimalarial activity of prenylated flavonoids from Erythrina fusca. Journal of Natural Medicines, 62, 217-220. https://doi.org/10.1007/ s11418-007-0214-z.

26. Penna-Coutinho, J., Aguiar, A.C., Krettli, A.U. (2018). Commercial drugs containing flavonoids are active in mice with malaria and in vitro against chloroquine-resistant Plasmodium falciparum. Memorias do Instituto Oswaldo Cruz, 113, e180279. https://doi.org/10.1590/0074-02760180279.

27. Kren, V., Martinkova, L. (2001). Glycosides in medicine: "The role of glycosidic residue in biological activity". Current Medicinal Chemistry, 8, 1303-1328. doi.org/10.2174/0929867013372193.

28. Graziose, R., Grace, M.H., Rathinasabapathy, T., Rojas-Silva, P., Dekock, C., Poulev, A., Lila, M.A., Smith, P., Raskin, I. (2013). Antiplasmodial activity of cucurbitacin glycosides from Datisca glomerata (C. Presl) Baill. Phytochemistry, 87, 78-85. https:// doi.org/10.1016/j.phytochem.2012.11.025.

29. Ovenden, S.P., Cobbe, M., Kissell, R., Birrell, G.W., Chavchich, M., Edstein, M.D. (2011). Phenolic glycosides with antimalarial activity from Grevillea "Poorinda Queen". Journal of Natural 
Products, 74, 74-78. https://doi.org/10.1021/ np100737q.

30. Park, W.H., Lee, S.J., Moon, H.I. (2008). Antimalarial activity of a new stilbene glycoside from Parthenocissus tricuspidata in mice. Antimicrobial Agents and Chemotherapy, 52, 3451-3453. https://doi.org/10.1128/AAC.00562-08.

31. Pereira, D.M., Valentao, P., Pereira, J.A., Andrade, P.B. (2009). Phenolics: from chemistry to biology. Molecules, 14, 2202-2211. https://doi.org/10.3390/ molecules14062202.

32. Laphookhieo, S., Maneerat, W., Koysomboon, S. (2009). Antimalarial and cytotoxic phenolic compounds from Cratoxylum maingayi and Cratoxylum cochinchinense. Molecules, 14, 1389-1395. https://doi.org/10.3390/molecules14041389.

33. Morimoto, M., Cantrell, C.L., Khan, S., Tekwani, B.L., Duke, S.O. (2017). Antimalarial and antileishmanial activities of phytophenolics and their synthetic analogues. Chemistry $\mathcal{E}$ Biodiversity, $14 . \quad$ https://doi.org/10.1002/ cbdv.201700324.

34. Alson, S.G., Jansen, O., Cieckiewicz, E., Rakotoarimanana, H., Rafatro, H., Degotte, G., Francotte, P., Frederich, M. (2018). In-vitro and invivo antimalarial activity of caffeic acid and some of its derivatives. The Journal of Pharmacy and Pharmacology, 70, 1349-1356. https:// doi.org/10.1111/jphp.12982.

35. Moreau, R.A., Nystrom, L., Whitaker, B.D., Winkler-Moser, J.K., Baer, D.J., Gebauer, S.K., Hicks, K.B. (2018). Phytosterols and their derivatives: structural diversity, distribution, metabolism, analysis, and health-promoting uses. Progress in Lipid Research, 70, 35-61. https:// doi.org/10.1016/j.plipres.2018.04.001.

36. Irungu, B.N., Adipo, N., Orwa, J.A., Kimani, F., Heydenreich, M., Midiwo, J.O., Martin Bjoremark, P., Hakansson, M., Yenesew, A., Erdelyi, M. (2015). Antiplasmodial and cytotoxic activities of the constituents of Turraea robusta and Turraea nilotica. Journal of Ethnopharmacology, 174, 419-425. https://doi.org/10.1016/j.jep.2015.08.039.

37. Perumal, P., Sowmiya, R., Prasanna Kumar, S., Ravikumar, S., Deepak, P., Balasubramani, G. (2018). Isolation, structural elucidation and antiplasmodial activity of fucosterol compound from brown seaweed, Sargassum linearifolium against malarial parasite Plasmodium falciparum. Natural Product Research, 32, 1316-1319. https://doi.org/10.1080/14786419.2017.1342081.

38. Huang, M., Lu, J.J., Huang, M.Q., Bao, J.L., Chen, X.P., Wang, Y.T. (2012). Terpenoids: natural products for cancer therapy. Expert Opinion on Investigational Drugs, 21, 1801-1818. https:// doi.org/10.1517/13543784.2012.727395.

39. Ludwiczuk, A., Skalicka-Wozniak, K., Georgiev, M.I. (2017). Terpenoids. Pharmacognosy, 233266. https://doi.org/10.1016/b978-0-12-8021040.00011-1.

40. Saewan, N., Sutherland, J.D., Chantrapromma, K. (2006). Antimalarial tetranortriterpenoids from the seeds of Lansium domesticum Corr. Phytochemistry, 67, 2288-2293. https:// doi.org/10.1016/j.phytochem.2006.07.005.

41. Chukwujekwu, J.C., Rengasamy, K.R., de Kock, C.A., Smith, P.J., Slavetinska, L.P., van Staden, J. (2016). Alpha-glucosidase inhibitory and antiplasmodial properties of terpenoids from the leaves of Buddleja saligna Willd. Journal of Enzyme Inhibition and Medicinal Chemistry, 31, 63-66. https://doi.org/10.3109/14756366.2014.1003927.

42. Greve, H.L., Kaiser, M., Brun, R., Schmidt, T.J. (2017). Terpenoids from the oleo-gum-resin of Boswellia serrata and their antiplasmodial effects in vitro. Planta Medica, 83, 1214-1226. https:// doi.org/10.1055/s-0043-116943.

43. Lacaille-Dubois, M.A., Wagner, H. (1996). A review of the biological and pharmacological activities of saponins. Phytomedicine, 2, 363386. doi:10.1016/s0944-7113(96)80081-x.

44. Ohigashi, H., Huffman, M.A., Izutsu, D., Koshimizu, K., Kawanaka, M., Sugiyama, H., Kirby, G.C., Warhurst, D.C., Allen, D., Wright, C.W., David Phillipson, J., Timon-David, P., Delmas, F., Elias, R., Balansard, G. (1994). Toward the chemical ecology of medicinal plant use in chimpanzees: The case of Vernonia amygdalina, a plant used by wild chimpanzees possibly for parasite-related diseases. Journal of Chemical Ecology, 20, 541-553. https://doi.org/10.1007/ BF02059596.

45. Traore, F., Faure, R., Ollivier, E., Gasquet, M., Azas, N., Debrauwer, L., Keita, A., Timon-David, P., Balansard, G. (2000). Structure and antiprotozoal activity of triterpenoid saponins from Glinus oppositifolius. Planta Medica, 66, 368371. https://doi.org/10.1055/s-2000-8551.

46. Akanbi, O.M., Elekofehinti, O., Olatokunbo, A., Adejuyigbe, A., Jegede, A. (2018). Anti-malarial activity of total aaponins from Terminalia avicennioides and its effect on liver and haematological of infected mice. Drug Designing, 7, 161. https://doi.org/10.4172/2169-0138.1000161.

47. Shakya, A., Chaudary, S.K., Garabadu, D., Bhat, 
H.R., Kakoti, B.B., and Ghosh, S.K. (2020). A Comprehensive Review on Preclinical Diabetic Models. Current Diabetes Reviews, 16, 104-116. https://

doi.org/10.2174/1573399815666190510112035.

48. Vanlalhriatpuii, C., Zothantluanga, J.H., Bhat, H.R., Shakya, A. (2020). Preclinical research techniques for investigating therapeutic leads against gastrointestinal ulcer. Current Trends in Pharmaceutical Research, 7, 65-89.

49. Zothantluanga, J.H., Lalnunpuii, H.S., Bhat, H.R., and Shakya, A. (2019). Awareness on the possible adverse effect of Garcinia cambogia: A scientific approach. Science Vision, 19, 120-133. https:// doi.org/10.33493/scivis.19.04.02.

50. Paul, S., Hmar, E.B.L., Zothantluanga, J.H., and Sharma, H.K. (2020). Essential oils: a review on their salient biological activities and major delivery strategies. Science Vision, 20, 54-71. https://doi.org/10.33493/scivis.20.02.01.

51. Shanks, G.D. (2016). Historical review: problematic malaria prophylaxis with quinine. The American Journal of Tropical Medicine and Hygiene, 95, 269-272. https://doi.org/10.4269/ ajtmh.16-0138.

52. Kim, D.Y., Choi, B.Y. (2019). Costunolide-A bioactive sesquiterpene lactone with diverse therapeutic potential. International journal of molecular sciences, 20, 2926. https://doi.org/10.3390/ ijms20122926.

53. Efferth, T., Romero, M.R., Wolf, D.G., Stamminger, T., Marin, J.J., Marschall, M. (2008). The antiviral activities of artemisinin and artesunate. Clinical Infectious Diseases, 47, 804-811. https:// doi.org/10.1086/591195.
54. Rudrapal, M., Chetia, D. (2020). Virtual screening, molecular docking and QSAR studies in drug discovery and development programme. Journal of Drug Delivery and Therapeutics, 10, 225-233. https:// dx.doi.org/10.22270/jddt.v10i4.4218.

55. Sinha, S.K., Prasad, S.K., Islam, M.A., Gurav, S.S., Patil, R.B., AlFaris, N.A., Aldayel, T.S., AlKehayez, N.M., Wabaidur, S.M., and Shakya, A. (2020). Identification of bioactive compounds from Glycyrrhiza glabra as possible inhibitor of SARS-CoV-2 spike glycoprotein and nonstructural protein-15: A pharmacoinformatics study. Journal of Biomolecular Structure and Dynamics, 1-15. https:// doi.org/10.1080/07391102.2020.1779132.

56. Brusotti, G., Cesari, I., Dentamaro, A., Caccialanza, G., Massolini, G. (2014). Isolation and characterization of bioactive compounds from plant resources: the role of analysis in the ethnopharmacological approach. Journal of Pharmaceutical and Biomedical Analysis, 87, 218-228. https://doi.org/10.1016/j.jpba.2013.03.007.

57. Novaes, R.D., Leite, J.P.V. (2011). Ethnopharmacology as current strategy in the search of novel anti-ulcerogenic drugs: case of a Brazillian medicinal plant (Maytenus ilicifolia Mart. ex. Reissek). In Jianyuan Chai (ed), Peptic Ulcer Disease. Rijeka, Croatia; Shanghai, China: IntechOpen, pp. 375-400. Available from: http:// www.intechopen.com/books/peptic-ulcer-disease/ ethnopharmacology-as-current-strategy-in-thesearchof-novel-anti-ulcerogenic-drugs-case-of-abrazil. 